06

\title{
Влияние поверхностной обработки фемтосекундным импульсным лазерным излучением на механические свойства субмикрокристаллического титана
}

\author{
(C) Ю.Р. Колобов, ${ }^{1,2}$ Е.А. Корнеева, ${ }^{3}$ И.Н. Кузьменко, ${ }^{1}$ А.Н. Скоморохов, ${ }^{4}$ С.И. Кудряшов, ${ }^{5,6}$ A.A. Ионин, ${ }^{5}$ \\ C.В. Макаров, ${ }^{5,6}$ А.Ю. Колобова, ${ }^{2,7}$ C.С. Манохин, ${ }^{1,2}$ В.И. Бетехтин ${ }^{8}$, А.Г. Кадомцев ${ }^{8}$
}

${ }^{1}$ Белгородский государственный национальный исследовательский университет, 308015 Белгород, Россия

${ }^{2}$ Институт проблем химической физики РАН,

142432 Черноголовка, Россия

${ }^{3}$ Объединенный институт ядерных исследований,

141980 Дубна, Московская обл., Россия

${ }^{4}$ ГНЦ РФ - Физико-энергетический институт,

249033 Обнинск, Калужская обл., Россия

${ }^{5}$ Физический институт им. Лебедева РАН,

119991 Москва, Россия

${ }^{6}$ Университет ИТМО,

199034 Санкт-Петербург, Россия

${ }^{7}$ Национальный исследовательский технологический университет «МИСИС», 119991 Москва, Россия

${ }^{8}$ Физико-технический институт им. А.Ф. Иоффре РАН,

194021 Санкт-Петербург, Россия

e-mail: kolobov@bsu.edu.ru

(Поступило в Редакцию 31 мая 2017 г.)

Исследовано влияние обработки фемтосекундным лазерным излучением на механические свойства пластинчатых образцов субмикрокристаллического титанового сплава ВТ1-0 при активной деформации растяжением и усталостных испытаниях методом консольного изгиба.

DOI: 10.21883/JTF.2018.03.45597.2367

\section{Введение}

Известно, что среди современных металлических биоматериалов для хирургических имплантатов широкую перспективу применения имеет субмикрокристаллический (СМК) или наноструктуриванный (НС) нелегированный титан [1]. Формирование СМК и НС состояний в сплавах титана приводит к значительному улучшению комплекса их механических, физико-химических и других свойств, в том числе необходимых для их использования в качестве материала для медицинских имплантатов в травматологии, ортопедии, стоматологии и других областях медицины и техники.

Перспективным направлением для повышения биосовместимости СМК титана с биологическими тканями является модификация поверхности с использованием импульсных лазеров фемтосекундной длительности. Фемтосекундное лазерное облучение (ФЛО) обеспечивает меньшее загрязнение по сравнению с другими методами поверхностной обработки, обладает высокой технологичностью, применимо для обработки деталей со сложной поверхностью. Важным преимуществом лазерных импульсов с ультракороткой фемтосекундной длительностью является малая глубина (менее микрометра) зоны теплового воздействия [2]. Это позволяет осуществлять модификацию тонких приповерхностных слоев практи- чески без разогрева объема материала, который обычно сопровождается разупрочнением вследствие деградации СМК и НС состояний или полного их устранения вследствие развития процессов возврата и рекристаллизации. По этой причине применение фемтосекундного лазера особенно актуально для модификации поверхности титановых сплавов в СМК и НС состояниях, поскольку развитие указанных выше процессов, протекающих при повышенных температурах, приводит к уменьшению характеристик прочности рассматриваемых материалов, характерных для крупнозернистой структуры $[3,4]$.

Управляемое изменение рельефа поверхности путем проведения ФЛО является перспективным направлением повышения остеоинтеграции, поскольку нанорельеф поверхности особенным образом влияет на поведение различных типов клеток, а именно способствует повышению биоактивности остеобластов $[5,6]$. Управляемое изменение рельефа поверхности металлических имплантатов посредством ФЛО и её влияние на их биосовместимость являлись предметом ряда исследований поверхностной обработки путем ФЛО [5-7]. Однако вопрос о влиянии ФЛО на механические свойства титановых сплавов на сегодняшний день мало изучен. В настоящей работе проведено исследование влияния ФЛО на механические свойства субмикрокристаллического титана BT1-0. 

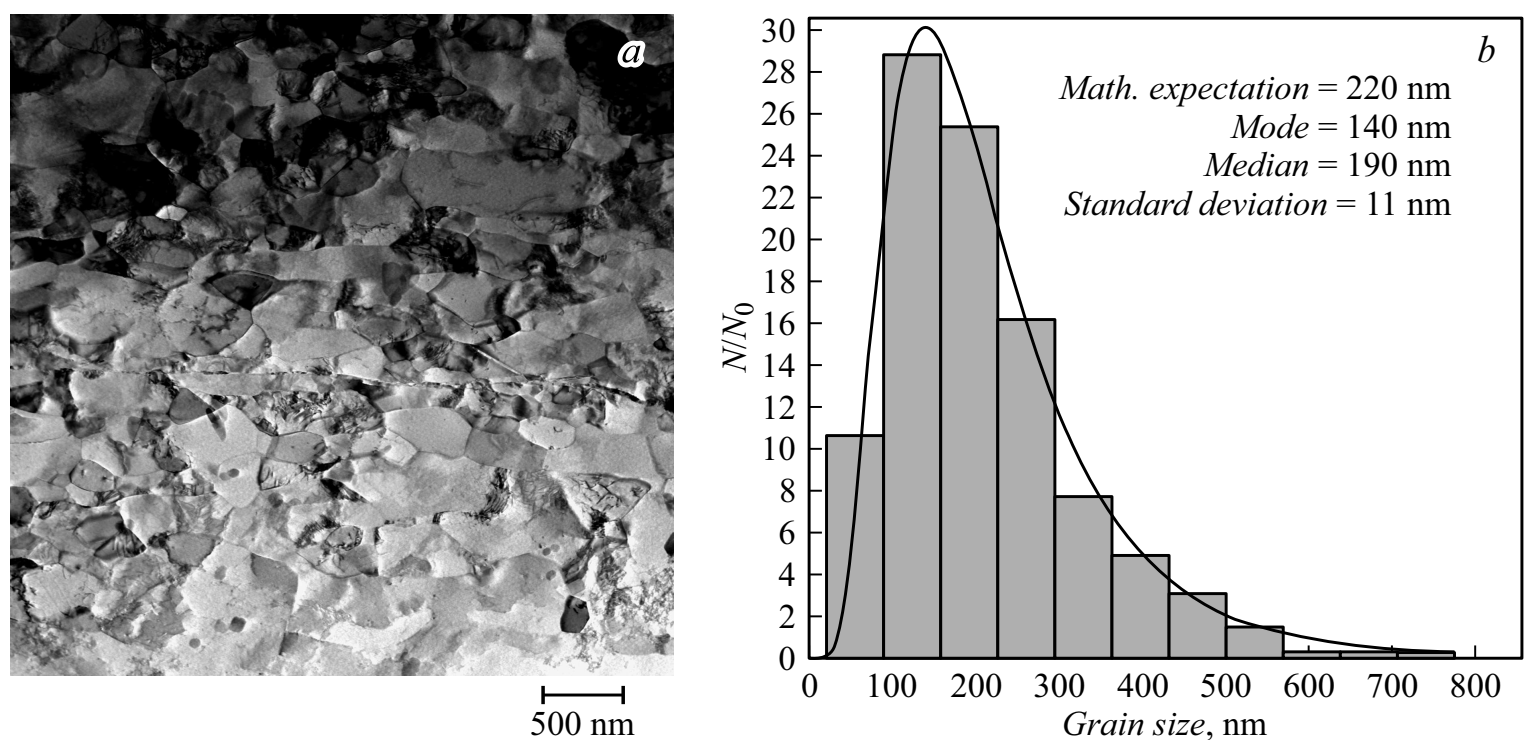

Рис. 1. Образец титана ВТ1-0 в исходном субмикрокристаллическом состоянии: $a$ - микроструктура (ПРЭМ), $b-$ гистограмма распределения зерен по размерам.

\section{Материалы и методы исследования}

Исследование механических свойств проведено на СМК титановом сплаве ВТ1-0 в исходном состоянии и после поверхностной модификации фемтосекундным лазерным излучением. Субмикрокристаллическое состояние с однородной глобулярной структурой со средним размером зерна $\sim 220 \mathrm{~nm}$ (рис. 1) было получено в прутках диаметром $8 \mathrm{~mm}$ с использованием механикотермической обработки путем сочетания радиальносдвиговой, поперечно-винтовой и сортовой прокаток [8]. Для снятия остаточных макронапряжений (напряжения первого рода) пруток отжигался в муфельной печи Nabertherm LT 5/13/P330 на воздухе при температуpe $350^{\circ} \mathrm{C}$ в течение $3 \mathrm{~h}$. В дальнейшем из отожженного прутка вырезались образцы электроискровой резкой (на станке SODICK AQ 300L) в виде двухсторонних лопаток с рабочей частью $2 \times 0.5 \times 27 \mathrm{~mm}$ и $2 \times 0.2 \times 27 \mathrm{~mm}$ для проведения механических испытаний на растяжение и в виде пластин с рабочей частью $3 \times 0.6 \times 16 \mathrm{~mm}$ для проведения усталостных испытаний на симметричный консольный изгиб. Перед проведением поверхностной обработки лазерным излучением и испытаний на усталость образцы механически шлифовали и полировали с использованием установок LaboPol-5 (Struers).

Определение среднего размера зерен проводили методом случайных секущих $[9,10]$. Для построения гистограмм распределения зерен по размерам и их математической обработки использовали программное обеспечение „ImageScope“. На рис. 1, $b$ представлена гистограмма распределения зерен по размерам для титанового сплава ВТ1-0 в исходном состоянии, а также приведены значения рассчитанных статистических параметров. Установлено, что вид функции плотности распределения описывается логнормальным законом.

\section{Методика лазерной обработки}

В экспериментах по модификации поверхности СМК титана фемтосекундным лазерным излучением применяли линейно поляризованное излучение (центральная длина волны $\lambda \approx 744 \mathrm{~nm}$, ширина полосы генерации на полувысоте $12 \mathrm{~nm}$ ) фемтосекундной Ti:Sa лазерной установки „Авеста Проект“ с длительностью импульсов около $100 \mathrm{fs}$ (в области взаимодействия), энергией до $8 \mathrm{~mJ}$, частотой следования $10 \mathrm{~Hz}$. Значения энергии лазерного излучения были подобраны таким образом, чтобы избежать заметной деградации распределения плотности энергии на поверхности мишени, связанной с самофокусировкой в воздухе и сопутствующими ей эффектами хроматической эмиссии, филаментации и рассеяния на воздушной плазме.

Обработка проводилась в воздушной атмосфере при плотности энергии $F=0.3 \mathrm{~J} / \mathrm{cm}^{2}$ и скорости сканирования $v=18 \mu \mathrm{m} / \mathrm{s}$. Направление сканирования и вектора поляризации излучения были выбраны таким образом, чтобы периодическая структура параллельных бороздок, образующихся в результате лазерной модификации, была направлена вдоль пластины, т.е. параллельно оси растяжения при квазистатическом нагружении и оси растяжения-сжатия при циклической нагрузке.

Выбор режима модификации производился на основе результатов предыдущей работы авторов по структурированию СМК титана фемтосекундным лазерным излучением, в которой были получены различные типы рельефа в зависимости от плотности энергии лазерного излучения и скорости сканирования [11]. Такой режим модификации с выбранными параметрами $F=0.3 \mathrm{~J} / \mathrm{cm}^{2}$ и $v=18 \mu \mathrm{m} / \mathrm{s}$ является наиболее оптимальным ввиду того, что формирующиеся в этом случае рельефы приводят к улучшению биосовместимости. При этом на поверх- 
ности не образуется глубоких пор и трещин, которые могут являться концентраторами напряжений, ведущих к понижению прочностных характеристик материала, особенно при циклических нагрузках.

\section{Методика механических испытаний}

Механические испытания на усталость проводили на электродинамической испытательной машине Instron Electropuls 3000 в комплексе с одновременным исследованием вязкоупругих свойств исследуемого материала методом динамо-механического анализа (ДМА) [12]. Испытания на усталость проводили по схеме консольного изгиба с частотой колебаний $10 \mathrm{~Hz}$ при комнатной температуре в симметричном режиме (коэффициент асимметрии цикла $R=-1$ ) при жестком нагружении (при постоянной амплитуде стрелы прогиба). Размер рабочей части образца для испытаний составлял $0.60 \times 3.0 \times 16.0 \mathrm{~mm}$. Полученные значения амплитуды силы пересчитывали в напряжение по формуле

$$
\sigma=6 \frac{F l}{b h^{2}}
$$

где $F$ - амплитуда силы, действующая на образец, $l-$ длина рабочей части образца, $b$ и $h-$ ширина и толщина образца соответственно.

При испытаниях на усталость фиксировались мгновенные значения силы (нагрузки) и перемещения (деформации) (рис. 2), что позволило провести ДМА методом корреляции. В этом методе определяется разность фаз между периодическими изменениями нагрузки и деформации, получившей название „угол потерь“, обозначаемой обычно как $\varphi$.

Измеряемая величина тангенса угла потерь $\operatorname{tg} \varphi$ характеризует рассеяние энергии $\Delta W$ колебаний за счет неупругих внутренних микропроцессов в твердом теле

$$
\operatorname{tg} \varphi=\frac{1}{2 \pi} \frac{\Delta W}{W}
$$

где $\Delta W / W$ - часть энергии, которую при вынужденных колебаниях необходимо ввести в колебательную систему за один период для поддержания полной энергии

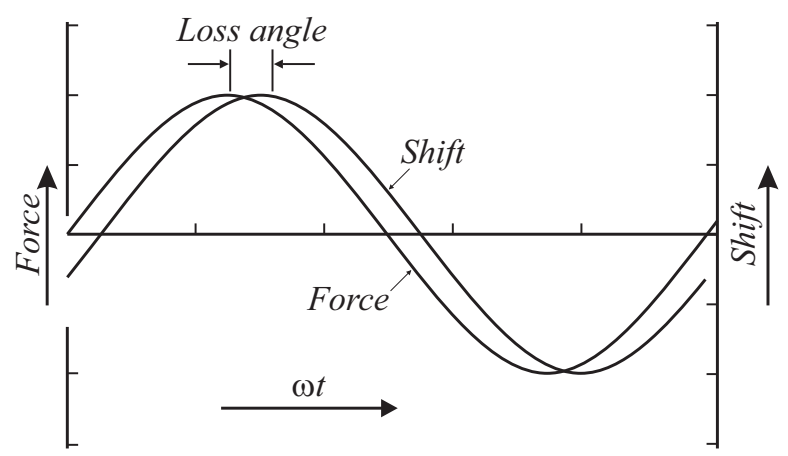

Рис. 2. Угол потерь $\varphi$ между приложенной нагрузкой $\varphi_{\sigma}$ и перемещением $\varphi_{\varepsilon}$. колебаний $W$ постоянной. Рост значения $\operatorname{tg} \varphi$ свидетельствует об увеличении интенсивности или появлении новых неупругих процессов, сопровождающих циклическую деформацию твердого тела; например, таких как возврат и микропластическая деформация, рост трещин и других [13].

Испытания на растяжение проводили на электромеханической испытательной машине Instron 5882 со скоростью деформации $1.5 \mathrm{~mm} / \mathrm{min}$ с использованием экстензометра с рабочей длиной $10 \mathrm{~mm}$.

Морфологию поверхности и элементный состав обработанных образцов исследовали с помощью сканирующего электронного микроскопа Quanta 600FEG с полевой эмиссией.

\section{Результаты экспериментов и их обсуждение}

Морфология и поперечный шлиф обработанной воздействием ФЛО поверхности титана представлены на рис. 3.

Режимы лазерной обработки подробно изучены в работе [11], где и описана детально формирующаяся при такой обработке структура. Последняя представляет упорядоченную структуру с характерным микро- и нанорельефом, в том числе отчетливо проявляющихся бороздок, параллельных направлению сканирования.

Деформационные кривые, полученные при растяжении пластин СМК титана толщинами 0.2 и $0.5 \mathrm{~mm}$ с лазерно-модифицированной поверхностью и в исходном состоянии (без модификации), представлены на рис. 4. Как видно из этого рисунка, связанные с лазерной модификацией изменения поверхности и приповерхностных слоев практически не оказывают влияния на такие характеристики исследуемого материала, как пределы прочности и текучести, модуль Юнга. Последний в первом приближении можно оценить по наклону линейного участка деформационной кривой $\sigma-\varepsilon$. Однако все образцы с лазерной модификацией поверхности показали заметно большую пластичность по сравнению с образцами без обработки лазером.

На рис. 5 приведены синхронно записанные результаты измерения максимального напряжения в цикле $\sigma$ (кривая 1) и тангенса угла потерь (кривая 2) в зависимости от количества циклов. Как видно из кривой циклического упрочнения, представленной на рис. 5 (кривая 1), максимальное напряжение в цикле (при фиксированной величине стрелы прогиба) остается практически неизменным и только перед разрушением уменьшается. Величина $\operatorname{tg} \varphi$ (кривая 2) тоже остается длительное время практически неизменной и только перед разрушением резко увеличивается.

Таким образом, начало разрушения образца при циклическом разрушении фиксируется как по кривым циклического упрочнения (разупрочнения), так и по па- 
$a$

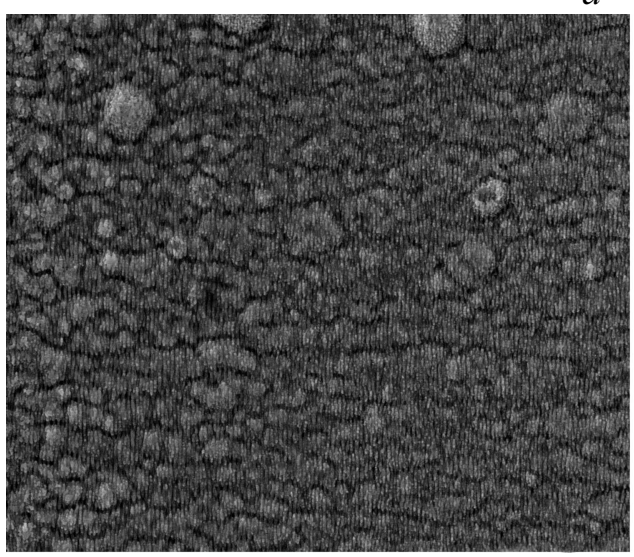

$20 \mu \mathrm{m}$

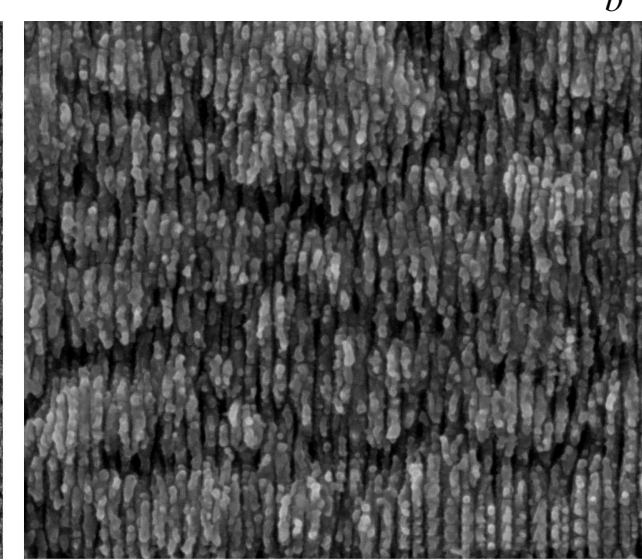

$5 \mu \mathrm{m}$

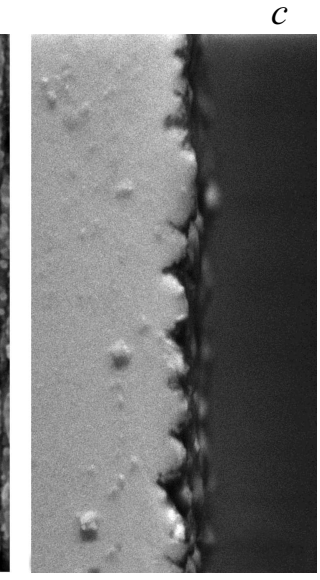

$20 \mu \mathrm{m}$

Рис. 3. Морфология поверхности титана ВТ1-0 после обработки фемтосекундным лазерным ИК излучением: $a-\times 5000, b-$ $\times 20000, c-$ поперечный шлиф $\times 5000$.

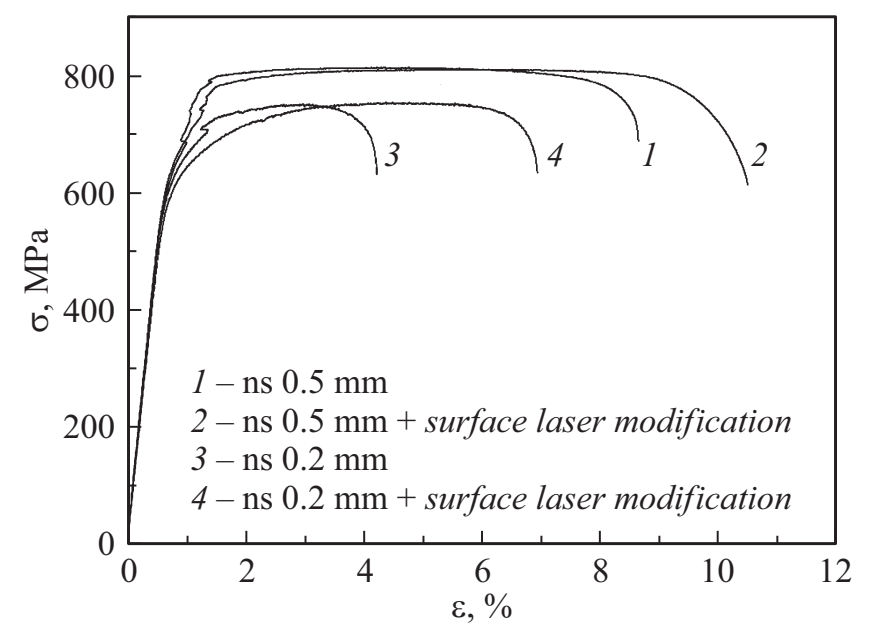

Рис. 4. Деформационные кривые для СМК-титана ВТ1-0 толщиной 0.2 и $0.5 \mathrm{~mm}$ с лазерной модификацией поверхности в сравнении с деформационными кривыми для СМК титана в исходном состоянии (без модификации).

дению амплитуды напряжения и росту тангенса угла потерь.

На рис. 6 приведена зависимость тангенса угла потерь (значения взяты в области независимости тангенса угла потерь от числа циклов (рис. 4)) от относительной близости максимального напряжения в цикле к пределу текучести данного материала при растяжении $\left(\sigma_{0.2}-\sigma_{\max }\right) / \sigma_{0.2}$. Как видно из приведенных данных, тангенс угла потерь уменьшается при уменьшении максимального напряжения в цикле относительно предела текучести. Это соответствует уменьшению интенсивности микропластической деформации при уменьшении максимального напряжения в цикле, что качественно подтверждается данными по увеличению количества циклов до разрушения при понижении максимального напряжения в цикле.

Для определения предела выносливости по результатам экспериментов были построены (рис. 7) зависимости максимального напряжения в цикле (напряжение бралось из кривых циклического упрочнения, аналогичных приведенным на рис. 5) от числа циклов до разрушения (диаграмма Веллера) для пластин титана BT1-0 в исходном состоянии ( $\square$ ) и после обработки поверхности лазером $(\boldsymbol{\square})$. Как видно из рис. 7, для всей области задаваемых напряжений образцы после обработки фемтосекундным лазерным излучением в среднем выдерживают большее количество циклов до разрушения, чем в исходном состоянии без лазерной обработки.

Полученные результаты исследований влияния поверхностной обработки фемтосекундным лазерным излучением на механические свойства исследуемого материала, а именно увеличение предела выносливости при

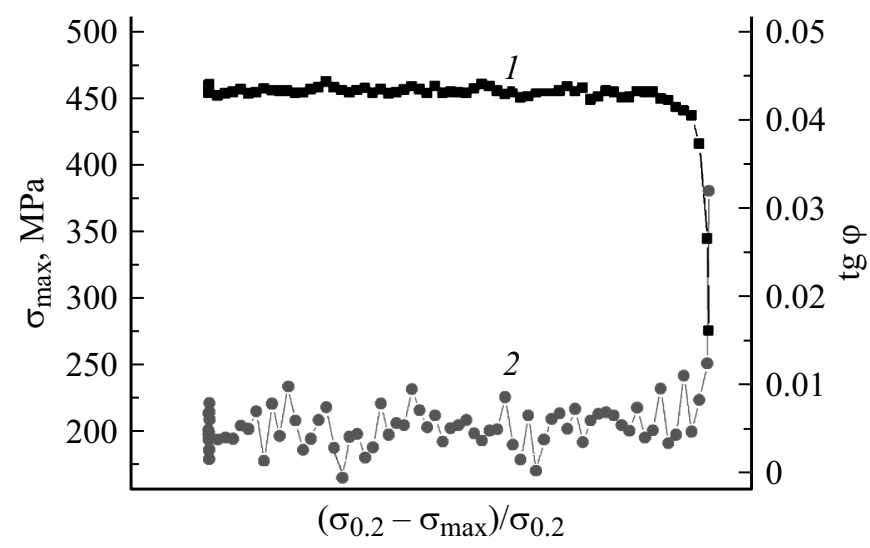

Рис. 5. Синхронно записанные результаты измерения максимального напряжения в цикле $\sigma(1)$ и тангенса угла потерь $\varphi(2)$ в зависимости от количества циклов деформации. 


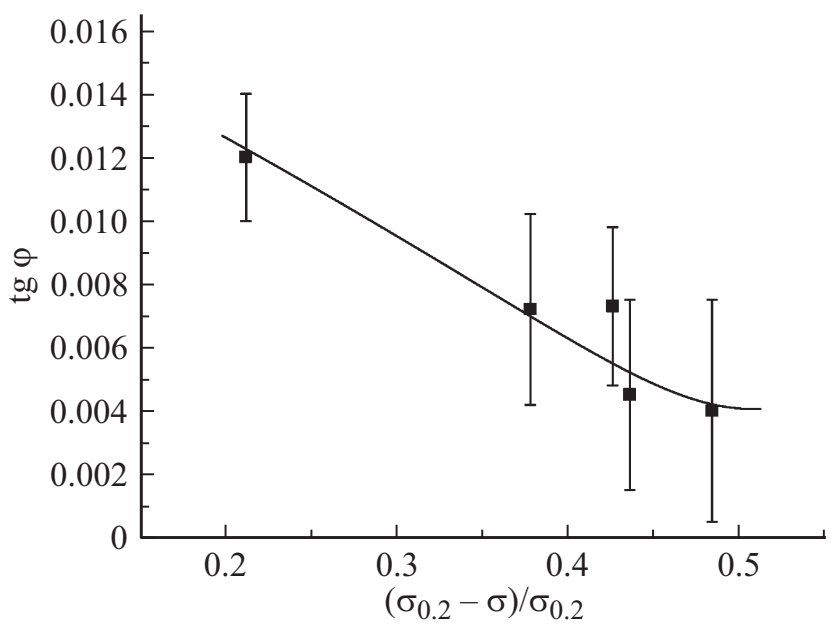

Рис. 6. Зависимость тангенса угла потерь $(\operatorname{tg} \varphi)$ от относительной близости максимального напряжения в цикле к пределу текучести.

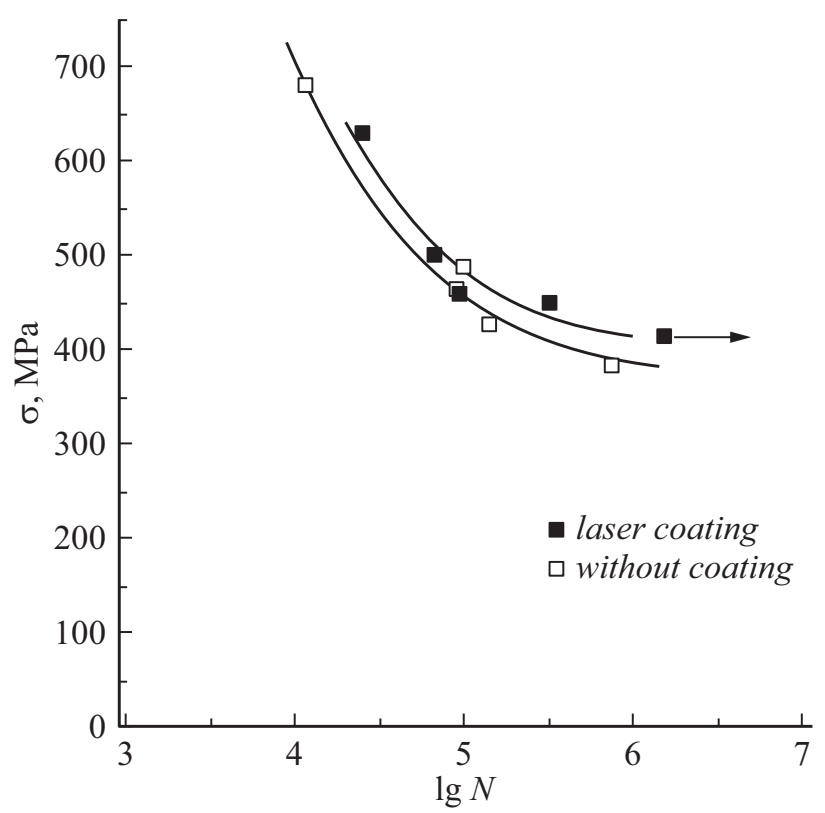

Рис. 7. Зависимость между максимальным напряжением в цикле и числом циклов до разрушения - диаграммы Веллера - для пластин наноструктурного титана ВТ1-0 толщиной $0.6 \mathrm{~mm}$ без покрытия $(\square)$ и с обработкой поверхности

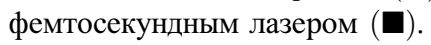

усталостных испытаниях и увеличение пластичности при квазистатических испытаниях на разрыв, коррелируют между собой, поскольку очевидно, что в материалах с улучшенной пластичностью распространение усталостных микротрещин более медленное, чем в хрупких. Таким образом, модифицирование поверхности имплантатов фемтосекундным лазерным излучением, заключающееся в образовании рельефа со сложной иерархической структурой, приводит не только к улучшению биосовместимости, но и к улучшению механических свойств.
Результаты механических испытаний на растяжение и усталость пластин толщиной $0.5-0.6 \mathrm{~mm}$ титанового сплава ВТ1-0 в СМК состоянии без покрытия и с обработкой лазером

\begin{tabular}{|c|c|c|c|c|c|}
\hline \multirow[b]{2}{*}{$\begin{array}{c}\text { Состояние } \\
\text { образца }\end{array}$} & \multicolumn{3}{|c|}{ Растяжение } & \multirow{2}{*}{$\begin{array}{c}\text { Предел } \\
\text { выносливости } \\
\sigma_{R N} \text { при } 10^{6} \\
\text { циклов, } \mathrm{MPa}\end{array}$} & \multirow[b]{2}{*}{$\sigma_{R N} / \sigma_{B}$} \\
\hline & $\begin{array}{l}\sigma_{0.2} \\
\mathrm{MPa}\end{array}$ & $\begin{array}{c}\sigma_{B}, \\
\mathrm{MPa}\end{array}$ & $\sigma_{B} / \sigma_{0.2}$ & & \\
\hline Исходный & $642 \pm 7$ & $805 \pm 7$ & 1.25 & 385 & 0.47 \\
\hline $\begin{array}{c}\text { Обработка } \\
\text { лазером }\end{array}$ & $652 \pm 7$ & $802 \pm 5$ & 1.23 & 422 & 0.53 \\
\hline
\end{tabular}

Необходимо заметить, что полученный эффект повышения сопротивления усталостии улучшения пластичности СМК титана ВТ1-0 после обработки поверхности фемтосекундным лазерным излучением выгодно показывает преимущество данного метода по сравнению с другими методами обработки поверхности сплавов титана. В частности, формирование на поверхности титановых сплавов биоактивных и биоинертных покрытий методом микродугового оксидирования приводит к уменьшению предела выносливости при испытаниях на усталость титанового сплава Ti-Al-Zr с контролируемой амплитудой нагружения по схеме растяжения-сжатия [14] и нелегированного титана (сплав Grade 4) по схеме нагружения 4-точечным изгибом (предела текучести и предела прочности) [15]. Микродуговое оксидирование обработки приводит также к уменьшению прочностных характеристик СМК титана ВТ1-0 при квазистатических нагрузках [16].

В сводной таблице приведены результаты механических испытаний на растяжение и усталость СМК пластин титанового сплава ВТ1-0 толщиной $0.6 \mathrm{~mm}$ в исходном состоянии и после обработки фемтосекундным лазерным излучением.

Как видно из таблицы, величины пределов текучести и прочности у образцов с лазерной обработкой и без нее практически не отличаются, а условный предел выносливости на базе $10^{6}$ циклов заметно выше у образцов после лазерной обработки поверхности.

\section{Выводы}

Обработка поверхности образцов субмикрокристаллического титана ВТ1-0 в форме пластин толщиной $0.6 \mathrm{~mm}$ лазерным излучением фемтосекундной длительности приводит к повышению условного предела выносливости (при базе испытаний $10^{6}$ циклов). При испытаниях на растяжение пластин СМК титана ВТ1-0 толщиной 0.5 и $0.2 \mathrm{~mm}$ лазерная обработка практически не меняет измеряемые величины пределов текучести и прочности, но существенно увеличивает величину деформации до разрушения.

С использованием метода ДМА установлено, что микропластическая деформация образцов исследуемого 
сплава при циклическом нагружении уменьшается при снижении максимального напряжения в цикле. При этом начало разрушения образца при циклических нагрузках сопровождается резким ростом величины микропластической деформации (тангенса угла механических потерь). Последнее может служить диагностическим признаком предельного ресурса работы материала.

Исследование выполнено за счет гранта Российского научного фонда (проект № 15-12-30010, в части исследования влияния обработки фемтосекундным лазерным излучением на механические свойства субмикрокристаллического титанового сплава ВТ1-0 при усталостных испытаниях методом консольного изгиба) и при поддержке Программы повышения конкурентоспособности НИЯУ МИФИ (в части отработки режима воздействия фемтосекундным лазерным излучением).

\section{Список литературы}

[1] Колобов Ю.Р. // Российские нанотехнологии. Нанообзоры. 2009. T. 4. № 11-12. C. 19-31.

[2] Le Harzic R. et al. // Appl. Phys. Lett. 2002. Vol. 80. P. 3886.

[3] Колобов Ю.Р., Липницкий А.Г., Иванов М.Б., Неласов И.В., Манохин С.С. // Изв. вузов. Физика. 2011. № 8. С. 77-95.

[4] Kolobov Yu.R., Ivanov M.B., Manokhin S.S., Erubaev E. // Inorg. Mater. 2016. Vol. 52. N 2. P. 128-133.

[5] Fadeeva E. et al. // Langmuir. 2011. Vol. 27. N 6. P. 3012 3019.

[6] Russell J. Crawford et al. // Adv. Colloid Interfac. 2012. Vol. 179. P. 142-149.

[7] Luong-Van E., Rodrigue I. et al. // J. Mater. Res. 2013. Vol. 28. N 2. P. $165-174$.

[8] Колобов Ю.Р., Иванов М.Б., Голосов Е.В., Пенкин А.В. Патент РФ 2389568.

[9] Салтыков С.A. Стереометрическая металлография. М.: Металлургия, 1986. $272 \mathrm{c}$.

[10] Степнов М.Н. Статистические методы обработки результатов механических испытаний. Справочник. М.: Машиностроение, 1985. $232 \mathrm{c}$.

[11] Ionin A. et al. // Laser Phys. Lett. 2013. Vol. 10. P. 045605.

[12] Фомин Н.Е., Юдин В.А., Киреев А.А. // Инновационное образование. 2013. № 4 (7). С. 129-137.

[13] Метод внутреннего трения в металловедческих исследованиях. Под редакцией М.С. Блантера, Ю.В. Пигузова. М.: Металлургия, 1991. 247 с.

[14] Wang Y.M., Zhang P.F., Guo L.X., Ouyang J.H., Zhou Y., Jia D.C. // Appl. Surf. Sci. 2009. Vol. 255. P. 8616-8623.

[15] Wheeler J.M., Collier C.A., Paillard J.M., Curran J.A. // Surf. Coat. Techn. 2010. Vol. 204. P. 3399-3409.

[16] Корнеева Е.А., Скоморохов А.Н., Колобов Ю.Р., Кузьменко И.Н., Храмов Г.В., Ракитянский В.В. // Композиты и наноструктуры. 2011. Т. 4. С. 32-42. 